\title{
PROFAE E LÓGICA NEOLIBERAL: ESTREITAS RELAÇÕES
}

\author{
PROFAE AND NEOLIBERAL LOGIC: CLOSE RELATIONS
}

\author{
Georgia Sobreira dos Santos Cêa 1 \\ Luiz Fernando Reis 2 \\ Solange Conterno ${ }^{3}$
}

Resumo O Projeto de Profissionalização dos Trabalhadores da Área de Enfermagem (Profae) representa, desde 2000, a principal política do Ministério da Saúde (MS) voltada para a qualificação da força de trabalho do setor. Sem negar tal condição, o esforço analítico deste artigo é guiado pelo exercício de compreensão do Profae a partir da sua condição de política social formulada e implementada em função dos preceitos e prescrições gerenciais típicos do Estado capitalista reformado segundo a orientação neoliberal. Este esforço constitui o objetivo principal deste trabalho. Inicialmente, o Profae é considerado a partir de sua visibilidade social, expressa na forma de projeto voltado para a qualificação de profissionais da área de enfermagem. Em seguida, a partir de uma breve contextualização dos dilemas em torno da formação desses profissionais no Brasil, problematiza-se a possibilidade de o Profae servir, efetivamente, de instrumento para a reversão dessa precariedade formativa. Este movimento permite buscar as mediações do Profae com a tipificação imposta às políticas de caráter neoliberal em curso e com as formas de privatização do fundo público, consideradas aqui como mecanismos implícitos ao seu financiamento. Por fim, são expostas reflexões acerca da instrumentalidade política e econômica do Profae, para além de sua aparência de simples projeto de profissionalização dos trabalhadores da área de enfermagem.

Palavras-chave Profae; qualificação profissional; Estado neoliberal.
Abstract The Professionalisation Project for Nurse Practitioners represents the Ministry of Health's main educational policy for such labour force since 2000 . Granted this condition, the analytical effort of this article is to understand Profae as a social policy formulated and implemented by management precepts and prescriptions typical of the neoliberal capitalist State. This is the main objetive of this paper. Firstly, the social visibility of Profae - considered as a project geared towards the educational training of nurse practitioners - will be examined. After that, the dilemmas that surround the formation of these professionals in Brazil will be briefly presented, followed by a discussion on the actual possibility of Profae serving as an instrument to revert the deficiencies in this formation. This allows us to seek the mediation between Profae and the typification imposed on the current neoliberal policies, as well as the privatisation forms of public funds, seen as implicit mechanisms for their financing. Finally, the political and economic instrumentality of Profae, beyond its aspect of a mere professionalisation project for nurse practitioners, is examined.

Keywords Profae; professional qualification; neoliberal State. 


\section{O Profae como um programa de qualificação 4}

O Profae foi oficialmente instituído em 15 de outubro de 1999, pela portaria $\mathrm{n}^{\circ} 1.262$ do MS. Institucionalmente, a formulação e a implementação do Profae resultaram de articulações do MS com o Ministério da Educação (MEC) e com o Ministério do Trabalho e Emprego (MTE). Internacionalmente, o Ministério da Saúde (MS) articulou-se com o Banco Interamericano de Desenvolvimento (BID), para a viabilização de cooperação financeira, e com a Organização das Nações Unidas para a Educação, a Ciência e a Cultura (Unesco), para o estabelecimento de cooperação técnica.

Para a execução do Profae foram previstos recursos da ordem de US\$ 370 milhões, sendo US\$ 185 milhões oriundos de um empréstimo junto ao BID5 e US\$ 185 milhões financiados com recursos do Tesouro Nacional. Destes, US\$ 130 milhões se originam do Fundo de Amparo ao Trabalhador (FAT) 6 e o restante, do MS. Segundo informações do MS, até março de 2004 o Profae havia executado financeiramente $49,75 \%$ do custo do projeto (MS, 2004). Coube ao BID, até então, a responsabilidade sobre $56 \%$ do valor executado.

A principal finalidade do Profae é a melhoria da qualidade dos serviços de saúde, por meio da qualificação de profissionais do setor. Por isso, o projeto tem como objetivo principal a oferta de oportunidades de profissionalização em grande escala, visando a atingir cerca de 225 mil auxiliares e 90 mil técnicos de enfermagem. O Profae vem sendo implementado em todo o Brasil, sob a responsabilidade do MS, por meio da coordenação da Secretaria de Gestão do Trabalho e da Educação na Saúde (SGTES). Constitui-se numa política pública que vem servindo como o principal instrumento para a qualificação da força de trabalho da área de enfermagem no Brasil.

Em função da diversidade de profissionais sem a devida qualificação, incluindo um expressivo contingente de profissionais que não concluíram o ensino fundamental, o Profae está estruturalmente organizado em dois componentes.

O Componente I volta-se para atividades de qualificação de auxiliares e atendentes de enfermagem, complementação da formação de auxiliares e técnicos de enfermagem e complementação do ensino fundamental de atendentes de enfermagem. $O$ curso de técnico de enfermagem é previsto para ser desenvolvido em 12 meses, com uma carga horária de 1.100 horas. O curso de complementação da qualificação profissional (para técnico e auxiliar de enfermagem) deve ser executado num prazo entre cinco e dez meses. Por fim, a complementação do ensino fundamental tem duração média de 18 meses.

O Componente II destina-se à garantia da estrutura necessária para o desempenho das variadas ações do primeiro componente. Para isso, são pre- 
vistas atividades voltadas para a formação de docentes e recursos humanos, certificação de competências, modernização de instituições e levantamento de informações sobre o mercado de trabalho.

Considerando o conjunto de atividades previstas pelo Profae, são estabelecidas as seguintes metas gerais: capacitação de 225 mil auxiliares de enfermagem e de 90 mil técnicos de enfermagem, conforme apresentado anteriormente; escolarização de auxiliares que não tenham concluído o ensino fundamental; modernização das 26 instituições integrantes da Rede de Escolas Técnicas do Sistema Único de Saúde (RET-SUS); formação de $12 \mathrm{mil}$ docentes (profissionais de saúde e enfermeiros) para a educação profissional na área da saúde; organização de um sistema de certificação de competências para as funções auxiliares da prática da enfermagem; sistematização de estudos do mercado de trabalho na área de enfermagem.

Esse conjunto de atividades desenvolve-se por meio da execução descentralizada do Profae, envolvendo entidades operadoras que podem executar ou contratar executoras para o desenvolvimento das atividades dos Componentes I e II. As operadoras e executoras são contratadas por meio de processos licitatórios lançados por editais do MS7. O processo de seleção dessas entidades é uma forma de controle da qualidade das várias atividades e cursos desenvolvidos no âmbito do Profae.

Os valores definidos nos editais consultados para efeito deste artigo (ver nota anterior) estão fixados da seguinte maneira: tem-se um custo-aluno definido entre $\mathrm{R} \$ 1.500,00$ e $\mathrm{R} \$ 2.000,00$ para os cursos de qualificação profissional de auxiliar de enfermagem; para o cálculo do valor dos cursos de complementação do ensino fundamental, é tomada como referência a quantia de $\mathrm{R} \$ 220,00$ por aluno.

Em função do baixo poder aquisitivo da maioria dos alunos do Profae, estes recebem um auxílio mensal no valor de $\mathrm{R} \$ 30,00$, nos termos da lei no $10.429 / 20028$, visando ao custeio de parte das despesas com transporte, necessárias ao deslocamento para o curso.

A avaliação do Profae é um processo contínuo, que tem resultado em produções referentes à execução do projeto nos diferentes estados (Bersusa, Zanin e Escuder, 2004; Gonçalves e Madeira, 2001; Peduzzi et al., 2003; Conterno e Reis, 2004) e em relatórios e produções avaliativas de abrangência nacional (Lima, 2002; MS, 2004; Avaliação, 2003; Unicamp, 2004)9.

Com base em informações do MS (2004), os principais resultados alcançados pelo Profae até março de 2004 foram os seguintes: formação de 148.656 mil alunos em auxiliar e técnico em enfermagem; 12 mil trabalhadores com o ensino fundamental concluído e cerca de 70 mil trabalhadores cursando este nível de ensino; envolvimento de aproximadamente 300 escolas de educação profissional, incluindo as técnicas do SUS (10\%), as públicas estaduais e federais $(22 \%)$, as particulares (58\%) e as do Sistema 
S10 $(10 \%)$. O processo de execução dos cursos conta com a supervisão e o monitoramento de uma rede de instituições denominadas agências regionais (25 entidades).

Embora as escolas da RET-SUS representem apenas 10\% das instituições executoras do Profae, a implementação do projeto resultou, para a rede, num aumento de $12 \%$ no estabelecimento de novos cursos, na criação de quatro novas escolas e na modernização e ampliação da capacidade instalada de $96 \%$ das escolas existentes. Além disso, a RET-SUS está envolvida com o Curso de Formação Pedagógica na Área da Saúde: Enfermagem, de pós-graduação lato sensu (especialização) ${ }^{11}$, formando profissionais já graduados e/ou licenciados em enfermagem para atuarem na educação profissional. Até março de 2004, algo em torno de oito mil enfermeiros docentes já haviam concluído o curso e outros quatro mil estavam por fazê-lo, perto, portanto, de se atingir a meta inicial de 12 mil profissionais de enfermagem qualificados para a docência na educação profissional.

Num encontro nacional sobre o Profae, ocorrido em Brasília, em 2002, os participantes, ao discutirem os aspectos mais relevantes do projeto, concordaram nos seguintes aspectos: gestão participativa, qualificação das instituições envolvidas como formadoras de recursos humanos para a saúde, impacto positivo da qualificação sobre as práticas profissionais e importância do processo licitatório para a qualidade das atividades formativas (Castro, 2003).

Para Silva e Biasoto Jr. (2002, p. 102), este último ponto é um dos principais destaques do Profae. Por isso, os autores o definem como um "projeto dotado de uma estratégia de implementação que consagra a interdisciplinaridade e a cooperação entre níveis de governo e organizações bastante incomuns dentre os projetos do Ministério da Saúde e de outras agências da área social".

Do ponto de vista formativo, Cury (2003) assinala que os cursos do Profae, ao contrário dos cursos livres ofertados pela política de qualificação profissional a cargo do MTE (na ocasião, o Plano Nacional de Qualificação do Trabalhador, o Planfor), permitem o reconhecimento da formação em nível nacional, chancelada pelo Conselho Nacional de Educação, uma vez que a formação pode estar articulada com os níveis de escolarização. Neste aspecto, merece relevo o processo de discussões sobre a constituição de um sistema de certificação de competências na área de enfermagem, especialmente para suas funções auxiliares ${ }^{12}$.

Esta breve caracterização do Profae, a partir de documentos e estudos que o tomam como objeto, serve, neste trabalho, para demonstrar que as análises vêm se restringindo a uma abordagem definida e direcionada pelos marcos técnico-operativos do projeto. O que se buscará é compreender o Profae para além de sua manifestação como um projeto voltado para a quali- 
ficação de profissionais da área de enfermagem. Serão buscados, a partir de então, elementos pouco explorados na literatura aqui citada, capazes de revelar dimensões do Profae que o articulam com a lógica neoliberal em curso.

\section{Antecedentes do Profae: a necessidade de formação dos profissionais da saúde}

Ao longo da década de 1980, em meio ao denso e conflituoso processo de redemocratização do país, ampliaram-se as discussões e os embates sobre as formas e os conteúdos que deveriam caracterizar a saúde pública no Brasil, sendo o SUS o mais emblemático resultado desse contexto. Em meio aos graves problemas da saúde pública estava a questão do nível de formação dos profissionais do setor.

No Brasil, a formação de pessoal auxiliar de saúde para funções de baixa complexidade, implementada pelas próprias instituições empregadoras, constitui-se numa tradição de muitos anos (Machado, 2002). A enfermagem não fugiu à regra geral e um grande contingente de trabalhadores, denominados atendentes de enfermagem, passa a ser contratado para o exercício de atividades de assistência à saúde sem qualquer formação escolar. Para a Associação Brasileira de Enfermagem (ABEn) (apud Bagnato, 1994, p. 105-106),

“com a falta de enfermeiros em muitos hospitais brasileiros, médicos se responsabilizavam por preparar atendentes e serventes, através de cursos rápidos no próprio hospital, os quais se limitavam, principalmente, ao ensino de técnicas de enfermagem".

Os atendentes de enfermagem, apesar de não reconhecidos pela legislação regulamentadora do exercício da enfermagem 13, vigente desde 1955, puderam exercer as suas funções sem maiores problemas até o ano de 1986. Entretanto, em 25 de junho daquele ano, é aprovada uma nova lei do exercício profissional de enfermagem, a lei federal $\mathrm{n}^{\circ}$ 7.498. Tal lei definiu que “a enfermagem é exercida privativamente pelo enfermeiro, pelo técnico de enfermagem, pelo auxiliar e pela parteira, respeitados os respectivos graus de habilitação" (Brasil, 1986).

Para Machado (2002), com a aprovação da lei federal $n^{0} 7.498 / 86$, os atendentes de enfermagem passaram a ser considerados uma categoria de trabalhadores em extinção. A referida lei determinou, em seu artigo 23, que os atendentes (categoria não reconhecida pela lei) que se encontravam executando tarefas de enfermagem, em virtude da carência de recursos hu- 
manos de nível médio nessa área, seriam autorizados pelo Conselho Federal de Enfermagem (Cofen) a exercerem atividades elementares de enfermagem, sob supervisão do enfermeiro, durante o prazo de dez anos. Decorrido esse prazo, ou seja, a partir de 1996, não seria mais permitido que atendentes de enfermagem 14 continuassem exercendo qualquer tipo de atividade de assistência à saúde da população. Caso isso ocorresse, seria considerado exercício ilegal da profissão.

A partir da vigência da lei $n^{\circ} 7.498 / 86$, as instituições de saúde estavam proibidas de contratar novos atendentes de enfermagem. De acordo com o MS (Oferta, 2001, p. 10), para os atendentes de enfermagem então regularmente empregados, foi dado um prazo de dez anos para que viessem a se qualificar formalmente como auxiliares de enfermagem.

Como forma de enfrentar a situação, medidas efetivas voltadas para a formação dos profissionais da saúde no país foram implementadas pelo Estado brasileiro nas décadas de 1980 e 1990, com destaque para as seguintes: Projeto de Formação em Larga Escala de Pessoal de Saúde, conhecido como Projeto Larga Escala; construção e constituição da RET-SUS; instituição dos Centros de Formação de Recursos Humanos em Saúde (Cefor) ${ }^{15}$.

Entretanto, apesar das intenções veiculadas pela lei $n^{0} 7.498 / 86$ e desse conjunto de ações no decorrer de quase duas décadas, não se conseguiu oportunizar a profissionalização ao imenso contingente de trabalhadores que, exercendo a função de atendentes de enfermagem, continuavam sendo inseridos no mercado de trabalho sem a formação profissional requisitada.

Essa situação pode ter determinado a promulgação da lei federal no 8.967, de 28 de dezembro de 1994, que alterou o artigo 23 da lei no 7.498/86, assegurando aos atendentes de enfermagem, admitidos antes da vigência desta lei (ou seja, antes de 1986), o exercício de atividades elementares de enfermagem. A partir da promulgação da lei $n^{\circ} 8.967 / 94$, deixou de existir um prazo legal obrigando os atendentes de enfermagem a buscar uma formação específica, regulamentada em lei, na área de enfermagem.

A partir de 1996, o Cofen, no uso de suas atribuições legais, passou a fiscalizar os trabalhadores que não estavam devidamente habilitados e amparados pela lei $n^{\circ} 8.967 / 94$, enquadrando-os no exercício ilegal da profissão. O MS admite que, para escapar dessa fiscalização, as instituições de saúde usaram - e usam até hoje - o subterfúgio de não registrar adequadamente esses atendentes de enfermagem, não amparados por lei, optando por uma relação informal de emprego, ou então registrando-os em outras funções, tais como auxiliares de serviços gerais ou braçais (Oferta, 2001).

Segundo o MS (Oferta, 2001), o aparato formador não acompanhou o crescimento da demanda por pessoal do setor e o contingente de pessoal não 
qualificado aumentou no período. A prática da contratação de pessoal não qualificado persistiu.

De acordo com informações do MTE, em 1997 os atendentes de enfermagem representavam um contingente de 115.530 trabalhadores formais. Esse número continuou crescendo e, em 2002, o MS informava que:

“É de aproximadamente 225 mil o número de trabalhadores que atuam no Sistema Nacional de Saúde e não têm a qualificação necessária para o exercício da profissão na área da enfermagem. Falta a 18 por cento desses trabalhadores concluir o ensino fundamental, que é pré-requisito para o curso de qualificação profissional. Outro fato que agrava ainda mais esse quadro: grande número de 'atendentes de enfermagem' atua sem a devida formação. É desviado para os serviços de enfermagem, depois de admitido para as funções administrativas, acarretando o exercício ilegal da profissão" (MS, 2002a, p. 8-9).

A existência de 225 mil atendentes sem a qualificação exigida em lei para o exercício de atividade profissional comprova, de fato, o flagrante desrespeito aos preceitos legais referentes ao exercício da enfermagem e de suas atividades auxiliares. Conforme antecipou Vieira (1990, p. 69), acabou por se desenvolver uma prática que parece ter perpetuado "a nomeação de atendentes pela simples troca do instrumento de trabalho (da vassoura para a seringa, e da cor do uniforme)", o que não contribui "com a resolutividade e qualidade requeridas para a rede de saúde, tendo-se em vista os princípios da Reforma Sanitária".

Dados recentes indicam que o desrespeito prossegue. Num estudo que analisou a implementação do Profae em quatro serviços de saúde na Bahia, os investigadores mostram que $21 \%$ dos profissionais sem qualificação matriculados em cursos do projeto haviam sido contratados recentemente (Peduzzi et al., 2003), a despeito da legislação e dos esforços em andamento para impedir o agravamento da situação.

Embora entre os 'infratores' da legislação do exercício das atividades de enfermagem haja instituições de saúde públicas e privadas, o que caracteriza a continuidade de uma prática típica do sistema de saúde no Brasil (Dantas e Aguillar, 1999), as instituições do setor privado foram praticamente 'anistiadas' da responsabilidade de promover e financiar a formação de seus contratados. O setor público, ao contrário, acabou por se responsabilizar duplamente, uma vez que: a) politicamente, coube ao Estado a iniciativa de propor uma alternativa para a regularização da formação dos atendentes de enfermagem dos setores público e privado; b) financeiramente, também ao poder público restou a responsabilidade pelos recursos para a efetivação dos procedimentos necessários ao cumprimento das exigências legais de formação daqueles profissionais. 
Diante disso, cabe indagar: em que medida a finalidade do Profae é, de fato, a melhoria dos serviços de saúde por meio da qualificação dos profissionais do setor de enfermagem, já que os esforços voltados para tal fim convivem, sem conflitos, com a continuidade da contratação indevida de profissionais? O enfrentamento desta questão exige uma compreensão do Profae que extrapole a sua condição de projeto de formação de profissionais da saúde e que busque as determinações de sua condição de política pública implementada segundo os atuais preceitos do Estado capitalista, condizentes com a nova ordem do capital.

Ao contrário do efervescente contexto político da década de 1980, em que as disputas e os enfrentamentos sociais eram processos legítimos, as soluções do Estado brasileiro para o dilema da formação dos trabalhadores da área de enfermagem foram engendradas num entorno político neoliberal, pouco afeito aos embates sociais, em que o Estado tem reconfigurada sua função reguladora.

\section{O Profae como política típica do Estado neoliberal}

Diante das orientações neoliberais de descentralização das ações estatais e de crescente restrição de verbas para os setores sociais, coube ao Estado brasileiro buscar formas políticas e financeiras de enfrentamento da questão da frágil formação profissional dos trabalhadores da área de enfermagem que não representassem ampliação da esfera pública, nem impacto sobre o orçamento do Estado. A resposta política e financeiramente adequada aos preceitos políticos e econômicos do neoliberalismo resultou na formulação do Profae, em 1999.

Após a afirmação política da orientação neoliberal resultante das disputas sociais dos anos finais da década de 1980, teve início um período de ajustes econômicos e políticos voltados para o enfrentamento dos problemas em curso no país. Para os reformadores neoliberais, o diagnóstico principal da crise econômica indicava que suas origens advinham do campo político. Dessa forma, na ótica neoliberal, a crise do Estado capitalista incluía, entre outros, o dilema entre o público e o privado, o qual ocasionava problemas de qualidade na ação e na intervenção estatal nas relações sociais, principalmente naquelas decisões governamentais consideradas estratégicas. A prescrição correlata indicou a constituição dos chamados 'mecanismos de quasemercados', prevendo o estabelecimento de relações competitivas na prestação de serviços públicos e criando um ambiente de "competição administrada" (Pereira, 1998).

Noronha e Soares (2001, p. 447), ao analisarem o caráter das políticas sociais da década de 1990 em face da reforma do Estado na perspectiva do 
neoliberalismo, apontam a configuração de um suposto "setor público nãoestatal" como uma das mais expressivas influências da orientação neoliberal sobre as políticas sociais. No caso da saúde, os autores destacam que a "privatização da saúde no Brasil tem várias faces: algumas mais explícitas e outras ocultas ou travestidas de 'modernização gerencial' no marco da já mencionada Reforma do Estado". Além da privatização da saúde em curso (em que a saúde pública se restringe a uma política para pobres), os autores advertem que uma "outra face tão perversa quanto, mas talvez mais 'camuflada', tem sido a privatização 'por dentro' do setor público" (Noronha e Soares, 2001, p. 448). Supomos que o Profae tanto se traveste quanto se camufla, ou seja, sob a sua aparência de projeto de formação profissional em saúde desenvolvem-se processos de gerenciamento dessa política social e de privatização da saúde e do fundo público.

Segundo Pereira (1995), para que a reforma gerencial do Estado brasileiro, iniciada na década de 1990, pudesse chegar a bom termo, era necessário atentar para três aspectos envolvidos em qualquer ação de governo: a definição da política, sua administração e seu financiamento.

É notória a ampla capacidade de articulação do Profae com outros setores e campos políticos: MS, MEC, MTE, BID, Unesco, Cofen, RET-SUS, universidades, além de mais de 300 instituições formadoras integram um conjunto que garante, por meio de ações coordenadas e congruentes, a implementação de uma política definida e determinada, cujos agentes, longe de meros executores, são partícipes na sua elaboração, execução e acompanhamento. Nesse sentido, o primeiro aspecto de uma política integrada aos preceitos do Estado-gerente vem sendo observado pelo Profae.

Pode-se afirmar, ainda, que o desenho operacional do Profae adequa-se aos preceitos da reforma gerencial do Estado brasileiro levada a cabo a partir da década de 1990, uma vez que, segundo aquela perspectiva, a nova configuração do Estado deve fazer uso da "estratégia da competição administrada em quase-mercados, para controlar as atividades sociais financiadas pelo Estado, por intermédio de entidades descentralizadas: as organizações públicas não-estatais" (Pereira, 1998, p. 18). Considerando as entidades operadoras e executoras do Profae, não é por acaso que $68 \%$ delas pertencem ao setor privado (Unicamp, 2004).

Além disso, o projeto desenvolve-se por meio de um processo que combina controle centralizado e execução descentralizada, no qual a capacidade de gestão do sistema de saúde vem confirmando a tendência de que "ao governo federal sejam reservadas apenas funções de normatização, prestação de assistência técnica e captação e repasse de recursos" (Silva e Biasoto Jr., 2002, p. 103). O processo licitatório serve, então, de instrumento para a concorrência administrada, estimulando e fortalecendo os espaços de quase-mercado. Tais elementos permitem identificar um funcionamento 
tipicamente gerencial do Profae, condizente com a perspectiva de política social impressa pela reforma do Estado brasileiro.

O tema do financiamento da saúde, ao longo da década de 1990, ocupou lugar de destaque no cenário nacional em diferentes momentos, atingindo praticamente toda a população, direta ou indiretamente. Algumas interpretações sugerem que a restrição de recursos para as áreas sociais, até hoje em curso, se deve ao fato de que

“(...) a Constituição [de 1988] criou um sistema de financiamento insuficiente para o tamanho do Estado nela definido. O resultado foi que o governo federal teve que criar, posteriormente à promulgação da Carta Magna, uma série de tributos para completar o financiamento do Estado, sem maior preocupação com regras econômicas de tributação, apenas visando à arrecadação" (Lima, 1999, p. 5).

Essa leitura enviesada e ideológica da democracia como um excesso indesejável obscurece a compreensão dos processos efetivos de restrição dos direitos sociais.

As opções econômicas do Estado brasileiro é que vão determinar, sobremaneira, as condições de financiamento das políticas sociais. Segundo Fiori (1998), as políticas dos governos passam a ser movidas pela growthfobia, de forma que a recessão da economia torna-se uma estratégia constante para a manutenção do equilíbrio das contas públicas. O controle das variáveis financeiras (principalmente da inflação) e cambiais (fluxo de entradas e saídas de moeda estrangeira) torna-se condição para a estabilidade financeira. Nesse contexto macroeconômico, o crescimento da economia é regulado em função e nos limites dos acordos (formais ou não) com os credores, ou seja, visa-se, prioritariamente, ao cumprimento das despesas referentes aos serviços da dívida. Mesmo que em detrimento e à custa da redução dos gastos sociais.

Noronha e Soares indicam que, em função desse movimento,

“A chamada área social no Brasil - com destaque para a área da saúde - constituise hoje no terreno mais conflitivo e exposto da nossa sociedade, na medida em que é particularmente sensível às condições econômicas de restrição financeira impostas pelas políticas de ajuste econômico também implantadas em nosso país" (Noronha e Soares, 2001, p. 446).

Para o tratamento da problemática do financiamento da saúde, o Estado brasileiro encaminhou uma série de ações. Em 1993, foi criado o Imposto Provisório sobre Movimentação Financeira (IPMF), transformado em Contribuição Provisória sobre Movimentação Financeira (CPMF) a partir de 1996. A obrigatoriedade da CPMF está prevista até 2007. Embora criados 
para financiar ações e serviços de saúde, é comum que esses recursos acabem se destinando a outros fins.

Outra medida voltada para a problemática do financiamento foi concretizada com a aprovação da emenda constitucional $n^{\circ} 29$, em 2000, que fixa os mínimos orçamentários para o financiamento de ações e serviços públicos de saúde. Segundo Noronha e Soares (2001, p. 449), a referida emenda não chega a representar impacto considerável nos recursos para a saúde pública, uma vez que ela "é (mais um) exemplo da capacidade de distorcer propostas antes defendidas pelos setores progressistas e transformálas em estratégias convenientes para o projeto neoliberal". Isto porque, originalmente, a idéia democrática, reivindicada pelos setores populares da sociedade civil e em disputa na sociedade política, previa a efetiva vinculação e ampliação de recursos para a saúde pública. Concluem os autores que,

“Mais uma vez, sob a aparência de que os recursos para a saúde aumentarão, e concebendo de forma distorcida uma aspiração de vinculação de recursos, o governo federal perpetra mais uma 'reengenharia', reduzindo sua obrigação e repassando para os estados e municípios a responsabilidade maior no financiamento do setor saúde" (Noronha e Soares, 2001, p. 449).

Além desses encaminhamentos paliativos, foi se tornando recorrente a tomada de empréstimos internos e externos, financiados por organismos multilaterais. Mattos (2001), analisando a relação entre as agências internacionais e as políticas de saúde ao longo da década de 1990, assevera que a oferta de idéias torna-se uma conduta mais valorizada do que o volume de recursos envolvidos nas transações, demonstrando que o cumprimento de determinadas condicionalidades assume maior importância para aquelas agências do que a liberação efetiva de recursos. Isso se aplica ao Profae.

No seu conjunto, as alternativas para o financiamento da saúde caracterizam-se, em essência, pelo fato de não interferirem na lógica macroeconômica recessiva, por não requererem ou resultarem em ampliação dos gastos públicos; ao contrário, a racionalidade intrínseca a tais medidas é orientada para a otimização da gestão de recursos, o que na prática deve significar redução de custos. Dessa forma, parece fazer sentido a afirmação de Pereira (1995, p. 3):

“O financiamento [da saúde pública] está sendo agora encarado de forma corajosa e realista pelo Ministro da Saúde [José Serra, na ocasião] (...) Ao privilegiar a descentralização, o governo federal se alinhará com as mais modernas tendências de gestão do Estado". 
Pelo conjunto das considerações sobre o financiamento tecidas até aqui, há elementos que indicam que o Profae é um exemplo desse alinhamento. É o que veremos a seguir.

\section{O financiamento do Profae como mecanismo de privatização do fundo público}

As primeiras discussões sobre o Profae envolveram, no âmbito do governo federal, representantes e técnicos do MS, MEC e MTE. O financiamento total do projeto (US\$ 370 milhões) previa, além da parcela de empréstimo do BID (US\$ 185 milhões), uma contrapartida nacional, que foi definida nos seguintes termos: US\$ 130 milhões oriundos do FAT e os demais US\$ 55 milhões a cargo do MS.

Segundo o MS (2004), até março de 2004, o Profae havia executado $49,75 \%$ do seu custo total. Os recursos executados tiveram como principal origem o BID (56\%). Da contrapartida nacional (identificada como 'recursos oriundos do Tesouro Nacional'), a principal fonte é o FAT.

A transferência de recursos do FAT para o MS, como forma de complementar recursos para este setor, não é um procedimento inaugurado pelo Profae16. Em 1993, o Conselho Deliberativo do Fundo de Amparo ao Trabalhador (Codefat) aprovou um empréstimo com recursos do FAT para o então Instituto Nacional de Assistência Médica da Previdência Social (Inamps). Em 1996, regularizando uma série de medidas provisórias, a lei ordinária $\mathrm{n}^{0}$ 9.322/96 autorizou novos empréstimos do FAT para o MS, no valor de $\mathrm{R}$ \$ 2,4 bilhões, visando ao pagamento de serviços assistenciais do SUS (atendimento ambulatorial e internações hospitalares, além de outras ações). A partir de 1999, essa transferência de recursos do FAT para o MS e deste para o setor privado, predominantemente, vem ocorrendo por intermédio do Profae. Desde 1993, o tema da transferência de recursos do FAT para o MS suscita discussões e debates no interior do Codefat, órgão gestor do fundo. Entretanto, as imposições e determinações do MS têm prevalecido.

A proposta de utilização dos recursos do FAT como contrapartida do governo brasileiro para o financiamento do Profae foi levada pela primeira vez ao Codefat por um representante do MS, em outubro de 1998, como um item 'extrapauta'; ou seja, os membros do Codefat não haviam sido comunicados formalmente de que a discussão do projeto ocorreria naquela reunião. Segundo informações ali prestadas pelo representante do MS, inicialmente o Profae estava estimado em US\$ 600 milhões, mas definiu-se por um orçamento de US\$ 370 milhões, sendo a metade oriunda de empréstimo junto ao BID e a outra metade oriunda de contrapartida do governo brasileiro: US\$ 130 milhões do FAT e o restante do MS (US\$ 55 milhões). Menos de um 
ano depois dessa primeira apresentação da proposta, o Codefat aprovou, ad referendum, na $58^{\mathrm{a}}$ reunião ordinária do conselho, em 28 de setembro de 1999, a parceria entre o FAT e o MS, com previsão de alocação de recursos, atendendo a uma condicionalidade para a continuidade das negociações daquele ministério com o BID. Em 15 de outubro de 1999, por fim, o Profae é oficializado pela portaria $\mathrm{n}^{\circ} 1.262$, do Gabinete do MS.

Nesse intervalo de tempo, o Profae foi pautado em três reuniões do Codefat. Em dezembro de 1998, quase dois meses depois da primeira apresentação do Profae ao conselho, uma nova investida do MTE junto ao Codefat objetivou apressar, sem sucesso, a aprovação da contrapartida com recursos do FAT, apresentando, inclusive, uma nota técnica do MTE constatando a viabilidade da aprovação e indicando a possibilidade do projeto do MS ser oportunamente incluído no orçamento do FAT. Em junho de 1999, por ocasião da discussão da proposta orçamentária do FAT para o ano seguinte, os conselheiros foram informados sobre as negociações entre MS, MTE e BID, visando ao acordo final do projeto do Profae. Na ocasião, o representante da Central Única dos Trabalhadores (CUT) no Codefat questionou a desproporcionalidade entre os recursos do fundo e a parcela sob a responsabilidade do MS, considerando que este tinha recursos próprios, definidos no orçamento da União e acrescidos pela CPMF. No debate, prevaleceram os inconsistentes argumentos do representante do MTE de que os recursos do fundo destinados ao MS voltavam-se para a qualificação do trabalhador, uma das frentes já financiadas pelo FAT. Na reunião seguinte, ocorrida em 29 de julho de 1999, um representante do MS detalhou a proposta orçamentária e programática do Profae, e o Codefat deliberou pela comunicação formal àquele ministério de sua aquiescência ao projeto. Em setembro de 1999, o Profae foi, enfim, oficialmente aprovado pelo Codefat.

Em outras ocasiões, o Profae voltou a ser tema do Codefat, em função da não coincidência entre os valores aprovados pelo conselho e os recursos efetivamente executados. Segundo o MS (2004), a partir de 2002 esta situação é amenizada pela aprovação de suplementações orçamentárias, mas a regularização do repasse dos recursos só ocorre a partir de 2004.

$\mathrm{O}$ atraso no repasse de recursos aparece nas avaliações nacionais do Profae como um dos principais problemas da execução do projeto, gerando dificuldades de ordens diversas (MS, 2002b; MS, 2004; Unicamp, 2004). Este fato certamente influenciou o MS na decisão de prorrogar o projeto até 2006, nova data prevista para sua conclusão.

Apesar de conturbadas, as discussões sobre o Profae no Codefat passam longe da problematização dos usos e destinações de um fundo público - o FAT - predominantemente para a iniciativa privada, a exemplo do que ocorria com o Planfor, principal política de formação dos trabalhadores a cargo 
do MTE até 2003 (Cêa, 2003). Ou seja, a descentralização das ações do governo para entidades integrantes do 'quase-mercado', que se apropriam do fundo público para a execução de atividades consideradas 'não-exclusivas' do Estado, é um fato encarado com naturalidade no interior do Codefat, até mesmo por aqueles representantes dos trabalhadores, os quais, em tese, deveriam ser os mais zelosos gestores do fundo.

Além da transferência direta dos recursos do FAT para o Profae, há uma outra via indireta de repasse. Trata-se do Programa de Expansão da Educação Profissional (Proep)17, desenvolvido pelo MEC de forma semelhante ao Profae, inclusive quanto ao financiamento. Em recente avaliação dos impactos do Profae nas escolas da RET-SUS (Unicamp, 2004), verifica-se que o financiamento dessa rede passa a contar, a partir da implementação do Profae, com significativos recursos do FAT, seja por via direta ou indireta, tendo, neste último caso, o Proep como mediador:

“O financiamento das atividades de Modernização e Fortalecimento das ETSUS [previstas pelo Componente II do Profae] provém de duas fontes: a primeira é o MS/Profae, com recursos da ordem de R $\$ 500$ mil para cada escola técnica; a segunda fonte provém do Ministério da Educação, através do Proep, que prevê a transferência de R\$ 2 milhões, em média, para cada Escola" (Unicamp, 2004, p. 10).

Numa espécie de divisão de responsabilidades financeiras, o estudo ainda demonstra que

“os recursos provenientes do MS/Profae financiam consultorias e serviços de capacitação do pessoal administrativo, enquanto os recursos do MEC/Proep se destinam a financiar a reforma e ampliação das instalações, assim como a aquisição de equipamentos" (Unicamp, 2004, p. 10).

Em ambos os casos, o FAT aparece como o principal recurso público sustentador dessas ações.

Considerando a abrangência nacional do Profae e o fato de que a formação dos profissionais da saúde no Brasil tem sido ofertada predominantemente pelo setor privado, como já vimos, este vem sendo o principal destino dos recursos do FAT. Talvez por isso possa se identificar a política de qualificação do MS como 'corajosa e realista', segundo a perspectiva do mercado como principal regulador social, em grande parte estimulado pelo uso privado dos recursos públicos. 


\section{Reflexões finais acerca do Profae}

Os dados oficiais do Profae e as produções que o tomam como objeto de avaliação, análise e reflexão permitem afirmar que o projeto é a mais expressiva política oficial de formação dos profissionais da área da saúde levada a cabo pelo MS - seja por seu conteúdo, seja por sua forma.

Concordamos que o Profae representa uma efetiva tentativa de enfrentamento da histórica problemática da formação dos trabalhadores da área da enfermagem no Brasil, por promover oportunidades de formação da força de trabalho a milhares de trabalhadores do setor, podendo, inclusive, estar contribuindo, mesmo que marginalmente, com a garantia de permanência no emprego para muitos deles. Reconhecemos os esforços e a competência das principais instituições e entidades envolvidas com o Profae. No entanto, mesmo reconhecendo estes avanços, não se pode desconsiderar que milhares de trabalhadores continuam sendo contratados em condições precárias, como se fazia décadas atrás. E não se pode atribuir a eles mesmos a responsabilidade pela infração aos preceitos legais que regulamentam as diferentes profissões relacionadas à prática da enfermagem. Como pensar em algo diferente disso, em se tratando da formação de profissionais da saúde?

O enfrentamento desse dilema abre a possibilidade de se constatar que, em se tratando de saúde pública, o projeto é expressão do distanciamento das perspectivas originais de um SUS descentralizado e abrangente, passível de efetivos mecanismos de controle social e organizado de modo a disponibilizar integralmente ações e serviços de saúde pública de qualidade.

Pelo menos quatro aspectos do Profae indicam a validade da assertiva acima. Primeiro, o projeto integra o movimento de retenção e redução dos recursos para a saúde pública e para a educação pública, às custas de outros recursos não incidentes sobre o orçamento da União. Em segundo lugar, o Profae é intermediário do financiamento, com recursos públicos, do aumento da produtividade do já lucrativo setor privado da saúde, por meio não só da qualificação dos profissionais deste setor - sem que isso represente custos para os empregadores -, mas também pelo uso privado de recursos públicos. Em terceiro lugar, o projeto fortalece o híbrido espaço do 'público não-estatal' - que se materializa, de fato, como espaço privado -, através da transferência de responsabilidades e de recursos públicos e da descentralização de ações para o setor privado. Por fim, o Profae, a exemplo do Planfor e do Proep, vem colaborando com a paulatina privatização do fundo público, ao canalizá-lo, sob o argumento da descentralização gerencial, para um espaço em que a competitividade transforma serviços em mercadorias, direitos em interesses, como se o espaço do político e do público tivesse se metamorfoseado num grande e totalizante mercado. 
Esses aspectos resultam de uma metodologia de análise, experimentada neste artigo, de compreensão das políticas sociais a partir e em função de suas vinculações com as orientações políticas macroeconômicas. Por isso o Profae foi aqui tomado como objeto de reflexão não por sua condição de política de formação de trabalhadores da saúde, mas por seu caráter de política pública típica dos tempos de neoliberalismo.

As considerações feitas até aqui não pretendem negligenciar ou mesmo diminuir a importância e a urgência de uma efetiva política de elevação dos níveis de formação dos trabalhadores da saúde, em especial daqueles que compõem seu principal contingente e que desempenham funções auxiliares da enfermagem. Sem dúvida, o direito do usuário a um atendimento de qualidade passa pela devida formação dos profissionais de enfermagem. $\mathrm{O}$ direito dos trabalhadores, por sua vez, passa pela possibilidade de acesso a oportunidades de formação inicial e em serviço de qualidade. Mas a garantia desses direitos não pode onerar o poder público em função do desrespeito e da falta de responsabilidade de gestores públicos e privados com a contratação do pessoal de enfermagem, em especial de auxiliares e atendentes.

A partir da lógica política e econômica destacada neste trabalho, a utilização do FAT como principal recurso público financiador do Profae, ao invés de representar um ganho para os trabalhadores de enfermagem, representa, de fato, uma forma de amparo e proteção ao setor privado que, graciosamente, pode contar com trabalhadores mais qualificados que, por meio de seu trabalho, permitem o aumento da produtividade e dos ganhos de um setor que está entre os mais lucrativos do mercado: o setor da saúde privada.

Se para os trabalhadores o Profae pode representar um 'investimento' na própria profissão, uma forma de ampliar a 'empregabilidade', para os empresários da saúde, ao contrário, o Profae tem significado um ganho financeiro oriundo, principalmente, de um fundo público voltado para o 'amparo dos trabalhadores'. Antes de ser um paradoxo, isto é um elemento constitutivo da natureza da política social representada pelo Profae, em função de suas estreitas relações com a lógica neoliberal. Nem mesmo o silêncio político e econômico em torno desse aspecto torna menor a gravidade histórica da situação. 


\section{Notas}

1 Professora do Programa de Pós-Graduação em Educação da Universidade Estadual do Oeste do Paraná (Unioeste). Doutora em Educação pela Pontifícia Universidade Católica de São Paulo (PUC-SP). Líder do Grupo de Estudos e Pesquisas sobre Trabalho, Estado, Sociedade e Educação (GP-Tese). <gecea@uol.com.br>

2 Professor do curso de Enfermagem da Universidade Estadual do Oeste do Paraná (Unioeste). Mestre em Educação pela Universidade Estadual de Maringá (UEM). Membro do Grupo de Estudos e Pesquisas sobre Trabalho, Estado, Sociedade e Educação (GP- Tese).<lfreis6@uol.com.br>

3 Professora do curso de Enfermagem da Universidade Estadual do Oeste do Paraná (Unioeste). Mestre em Educação pela Universidade Estadual de Maringá (UEM). Membro do Grupo de Estudos e Pesquisas sobre Trabalho, Estado, Sociedade e Educação (GP-Tese). <solareis@brturbo.com.br>

4 A caracterização sintética do Profae exposta nesta parte do trabalho tomou por base documentos do Ministério da Saúde (MS, 2002a; MS 2002b), além de informações e documentos disponíveis nos seguintes portais eletrônicos: Conselho Federal de Enfermagem (Cofen, 2006), Ministério da Saúde e Unesco (2006).

5 Acordo de Empréstimo n ${ }^{0}$ 1.215/OC-BR entre o governo brasileiro e o BID (BID, 2000 e 2001). Segundo este acordo, o término dos desembolsos estava previsto para setembro de 2004. Em função de questões de diversas ordens (contingenciamento orçamentário e financeiro, inadequação das formas de identificação e encaminhamento da demanda, necessidade de continuidade da oferta de cursos de ensino fundamental, má distribuição das escolas de formação profissional pelo território nacional, com prejuízo para as regiões Norte e Nordeste), o projeto foi prorrogado até setembro de 2006, incluindo o redirecionamento e a reformulação de algumas ações (MS, 2004).

6 O FAT é um fundo parafiscal, contábil, de natureza financeira, criado através da lei $n^{\circ} 7.998$, de 11 de janeiro de 1990, regulamentando o previsto na Constituição Federal. Sua principal responsabilidade é administrar as contribuições para o Programa de Integração Social (PIS) e para o Programa de Formação do Patrimônio do Servidor Público (Pasep), de modo a custear as chamadas políticas públicas de emprego, entre as quais se destacam o Programa Seguro-Desemprego e o Abono Salarial, além de diferentes programas e projetos que possam contribuir para o desenvolvimento econômico do país, como é o caso dos programas de geração de emprego e renda. O FAT é gestado de forma tripartite pelo Conselho Deliberativo do FAT (Codefat), reunindo três bancadas - governo, empresários e trabalhadores -, com quatro representantes cada. Para mais detalhes sobre o funcionamento e as 'tensões' relacionadas ao Codefat, ver Cêa (2005) e Fidalgo (1999).

7 Alguns modelos de editais podem ser encontrados em Profae (2001a, 2001b, 2001c e 2001d) e BID (2000 e 2001).

8 Inicialmente, a lei no 10.429/2002 previu, em seu artigo 1, o pagamento do auxílioaluno para os exercícios de 2002 e 2003, adotando os termos da medida provisória $\mathrm{n}^{\circ} 21$, de 8 de janeiro de 2002, regulamentada pelo decreto no 4.123/2002. O artigo 1 foi alterado inicialmente pela lei $\mathrm{n}^{\circ} 10.853 / 2004$ e, posteriormente, pela lei $\mathrm{n}^{\circ} 11.129 / 2005$ (que institui o ProJovem), de modo a garantir o pagamento do auxílio-aluno para os exercícios de 2004 e 2005, respectivamente. 
9 O trabalho de Lima (2002) consiste no relatório de um estudo encomendado pelo Sistema de Acompanhamento de Sinais de Mercado de Trabalho do Setor Saúde (Samets), no âmbito do Profae, que analisou a oferta de educação profissional de nível técnico em saúde, com destaque para a formação em enfermagem no Brasil. Na revista Formação (Profae, 2003), são apresentadas análises e reflexões acerca dos impactos do Profae na qualidade dos serviços de saúde, notadamente da positividade dos indicadores de qualidade dos serviços prestados após a profissionalização. O material da Unicamp (2004) é um relatório final de um estudo sobre as diferentes mudanças relativas ao fortalecimento e à modernização das escolas técnicas e centro formadores do SUS (ETSUS), em função da implementação do Profae. Uma síntese de diferentes aspectos da execução do programa até março de 2004 pode ser vista em MS (2004), documento em que são apresentadas justificativas para a necessidade de prorrogação da execução do Profae até 2006.

10 O sistema S é composto pelas seguintes instituições: Senai (Serviço Nacional de Aprendizagem Industrial), Sesi (Serviço Social da Indústria), Senac (Serviço Nacional de Aprendizagem Comercial), Sesc (Serviço Social do Comércio), Senar (Serviço Nacional de Aprendizagem Rural), Senat (Serviço Nacional de Aprendizagem em Transportes), Sest (Serviço Social de Transportes), Sebrae (Serviço Brasileiro de Apoio às Pequenas e Médias Empresas) e Sescoop (Serviço Nacional de Aprendizagem do Cooperativismo).

11 “O curso é oferecido a distância, coordenado pela Escola Nacional de Saúde Pública da Fundação Oswaldo Cruz, com momentos presenciais nos Núcleos de Apoio ao Docente implantados em 45 instituições de ensino superior, contemplando todas as unidades da Federação" (MS, 2004, p. 9).

12 Para ter acesso às discussões iniciais do MS sobre certificação de competências, consultar MS (2000). A certificação de competências é um procedimento da modalidade 'educação profissional', apontado pela LDB n' 9.394/96, especialmente no seu artigo 41. No decreto $\mathrm{n}^{0} 2.208 / 97$, a certificação de competências aparecia como uma forma de prosseguimento dos estudos (dispensa de disciplinas ou módulos), podendo haver equivalência com o nível técnico do ensino médio. O decreto $\mathrm{n}^{\circ} 5.154 / 2004$, que revogou o anteriormente citado, não trata da questão. De qualquer forma, a elaboração de um sistema nacional de certificação de competências é um processo em curso.

13 A lei federal $\mathrm{n}^{\circ} 2.604$, de 17 de setembro de 1955, ao regular o exercício da enfermagem profissional, determinou que poderiam exercer a enfermagem no Brasil: o enfermeiro, o obstetriz, o auxiliar de enfermagem, a parteira, os enfermeiros práticos ou práticos de enfermagem, amparados por decretos, e as parteiras práticas, também amparadas por decreto.

14 A resolução Cofen-186, de 20 de julho de 1995, definiu e especificou as atividades elementares de enfermagem que poderiam ser executadas sem a formação específica regulada em lei. De acordo com a resolução: "São consideradas atividades elementares de enfermagem aquelas atividades que compreendem ações de fácil execução e entendimento, baseadas em saberes simples, sem requererem conhecimento científico, adquiridos por meio de treinamento e/ou da prática, requerem destreza manual, se restringem a situações de rotina e de repetição, não envolvem cuidados diretos ao paciente, não colocam em risco a comunidade, o ambiente e/ou a saúde do executante, mas contribuem para que a assistência de enfermagem seja mais eficiente". 
15 Para uma maior compreensão dessas medidas, consultar Aguiar Neto e Soares (2004), Lima (2002) e Unicamp (2004).

16 As fontes utilizadas para esta parte do artigo, que trata do processo de discussão do Profae no interior do Codefat, foram atas de reuniões e resoluções do conselho. Os interessados em ter acesso aos detalhes desses documentos podem buscar mais esclarecimentos em Cêa (2003), Cêa, Conterno e Reis (2005), ou entrar em contato com os autores deste artigo.

17 O Proep é uma iniciativa do MEC que objetiva um novo modelo de educação profissional capaz de propiciar a ampliação de vagas e a diversificação da oferta de oportunidades de formação para o mercado de trabalho. Nesse sentido, o Proep atua no redimensionamento da educação profissional, envolvendo a adequação e atualização dos currículos, construção, ampliação e reforma da estrutura física, aquisição de equipamentos e materiais didáticos e capacitação de recursos humanos. Sua implementação também obedece aos princípios da centralização do controle e de descentralização da execução, a exemplo do Planfor e do Profae. O Proep é financiado com recursos do BID (US\$ 250 milhões), do FAT (US\$ 125 milhões) e do MEC (US\$ 125 milhões).

\section{Referências}

ANAGUIAR NETO, Zenaide; SOARES, Cássia B. 2004. A qualificação dos atendentes de enferma enfermagem: transformações no trabalho na vida. Revista Latino-Americana de Enfermagem, v. 12, n. 4, p. 614-622.

AVALIAÇÃO do impacto do Profae na qualidade dos serviços de saúde. 2003. Formação, n. 7, p. 5-21.

BAGNATO, Maria Helena S. 1994. Licenciatura em enfermagem: para quê? Tese de Doutorado, São Paulo: Faculdade de Educação, Unicamp.

BERSUSA, Ana Aparecida S.; ZANIN, Maria de Lourdes; ESCUDER, Maria Mercedes L. 2004. Quem é o aluno Profae? Revista Eletrônica de Enfermagem, v. 6, n. 1, p. 77-97.

BID (Banco Interamericano de Desenvolvimento). 2000. Empréstimo no 1215/OCBR. Aviso geral de contratações. Disponível em: <gostorgi.ru/z531-73.htm>. Acesso em: 13 set. 2005.

2001. Empréstimo no 1215/OC-BR. Sistemas de acompanhamento do mercado de trabalho. Disponível em: < gostorgi.ru/z553-87.htm>. Acesso em: 13 set. 2005.
BRASIL. 1955. Lei no 2.604, de 17 de setembro de 1955. Regula o exercício da enfermagem profissional.

. 1986. Lei no 7.498, de 25 de junho de 1986. Dispõe sobre a regulamentação do exercício da enfermagem e dá outras providências.

. 1994. Lei no 8.967, de 28 de dezembro de 1994. Altera a redação do parágrafo único do artigo 23 da lei no 7.498, de 25 de junho de 1986, que dispõe sobre a regulamentação do exercício da enfermagem e dá outras providências.

CASTRO, Janete L. de. (relat.). 2003. Tendências da avaliação em educação profissional. In: MS (Ministério da Saúde). $1^{o}$ Fórum Nacional do Profae: construindo uma política pública de formação profissional em saúde: relatório final. Brasília, parte 2, p. 163171.

CÊA, Georgia S. dos S. 2003. A qualificação profissional entre fios invisiveis: uma análise crítica do Planfor. Tese de Doutorado, São Paulo: Pontifícia Universidade Católica de São Paulo. 2005. Possibilidades e limites do tripartismo: o caso do Conselho Delibe- 
rativo do Fundo de Amparo ao Trabalhador (Codefat). In: VIII Simpósio em História: História, Poder e Práticas Sociais, Marechal Cândido Rondon. Anais. 1 CD-ROM.

CÊA, Georgia S. dos S.; CONTERNO, Solange de F. R.; REIS, Luiz Fernando. 2005. O Profae e a privatização do fundo público: considerações iniciais. In: XVII Jornada Cascavelense de Enfermagem: A atuação profissional da enfermagem e o compromisso ético. Cascavel. Anais. $1 \mathrm{CD}-\mathrm{ROM}$.

COFEN (Conselho Federal de Enfermagem). 2006. Profae. Disponível em: <www. portalcofen.gov.br/_novoportal/ section044.asp?InfoID $=\&$ EditionSectionID $=44 \&$ SectionParentID $=>$. Acesso em: 12 jan. 2006.

CONTERNO, Solange de Fátima R.; REIS, Luiz Fernando. 2004. A formação de trabalhadores de enfermagem de nível técnico implementada pelo Profae/MS no estado do Paraná. In: XVI Jornada Cascavelense de Enfermagem: A produção do conhecimento e a prática da enfermagem. Cascavel. Anais. $1 \mathrm{CD}-$ ROM.

CURY, Carlos J. 2003. Políticas Públicas na Formação Profissional. In: MS (Ministério da Saúde). $1^{o}$ Fórum Nacional do Profae: construindo uma política pública de formação profissional em saúde. Brasília: Ministério da Saúde, parte 1, p. 83-87. Relatório final.

DANTAS, Rosana A. S.; AGUILLAR, Olga M. 1999. Ensino médio e o exercício profissional no contexto da enfermagem brasileira. Revista Latino-Americana de Enfermagem, v. 7, n. 2, p. 25-32.

FIDALGO, Fernando. 1999. A formação profissional negociada: França e Brasil, anos 90. São Paulo: Anita Garibaldi.

FIORI, José Luís. 1998. Os moedeiros falsos. $4^{\mathrm{a}}$ ed. Petrópolis: Vozes.

GONÇALVES, Dalva C.; MADEIRA, Lélia Maria. 2001. O Profae em Minas Gerais: o trabalho da Agência Regional. Trabalho, Educação e Saúde, v. 1, n. 1, p. 153160.

LIMA, Edilberto Carlos P. 1999. Reforma tributária no Brasil: entre o ideal e o possível. Texto para discussão, n. 666.

LIMA, Júlio César F. (coord.). 2002. Análise da oferta de educação profissional de nivel técnico em enfermagem no Brasil. Rio de Janeiro: Fundação Oswaldo Cruz, v. 1. Relatório final.

MACHADO, Sílvio Cesar. 2002. Projeto de Profissionalização dos Trabalhadores da Área de Enfermagem (Profae): uma ánalise crítica. Trabalho de Graduação, Cascavel, PR: Universidade Estadual do Oeste do Paraná.

MATTOS, Ruben Araújo de. 2001. As agências internacionais e as políticas de saúde nos anos 90: um panorama geral da oferta de idéias. Ciência \& Saúde Coletiva, v. 6, n. 2, p. 377-389.

MS (Ministério da Saúde). 2001. Supervisão do Profae. Brasília. Documento de orientação.

2002a. Saúde: promovendo a educação profissional. Brasília: Profae.

. 2002b. $1^{o}$ Fórum Nacional do Profae: construindo uma política pública de formação profissional em saúde. Brasília: Ministério da Saúde. Relatório final.

Secretaria de Gestão do Trabalho e da Educação na Saúde. 2004. Informação técnica. Disponível em: $<$ www.retsus.epsjv.fiocruz.br/upload/ documento/NOTA \%20TECNICA \%20S OBRE $\% 20 A \%$ 20RENEGOCIACAO $\% 203 \% 20$ de $\% 2021 \% 20$ de $\% 20$ ju nho.doc >. Acesso em: 27 ago. 2005.

NORONHA, José C. de; SOARES, Laura T. 2001. A política de saúde no Brasil nos anos 90. Ciência \& Saúde Coletiva, v. 6, n. 2, p. $445-450$.

OFERTA de qualificação é necessária para melhorar atenção à saúde. 2001. Formação, n. 1, p. 9-14.

PEDUZZI, Marina et al. 2003. Características do contexto de trabalho da enfermagem. Formação, n. 7, p. 5-21.

PEDUZZI, Marina; ANSELMI, Maria Luiza. Avaliação do impacto do Profae na qualidade dos serviços de saúde. 2004. Disponível em: <http://www.opas. org.br/rh/admin/documentos/impac_ profae.pdf $>$. Acesso em: 27 ago. 2005. 
PEREIRA, Luiz Carlos B. 1995. Reforma administrativa do sistema de saúde. Disponível em: <www.datasus.gov.br/ cns/temas/MARE.htm $>$. Acesso em: 2 dez. 2005.

1998. Reforma do Estado para a cidadania: a reforma gerencial brasileira na perspectiva internacional. São Paulo: Ed. 34.

PROFAE (Programa de Profissionalização dos Trabalhadores da Área de Enfermagem). 2001a. Edital de convocatória pública de credenciamento de operadoras $\mathrm{n}^{\circ}$ 051/2000. Disponível em: $<$ dtr2001.saude.gov.br/bvs/publicacoes /profae_rn.pdf $>$. Acesso em: 15 out. 2005.

2001 b. Edital de convocatória pública de credenciamento de operadoras $\mathrm{n}^{\circ}$ 061/2000. Disponível em: <dtr2001. saude.gov.br/bvs/publicacoes/profae_ pb.pdf>. Acesso em: 15 out. 2005.

2001c. Edital de convocatória pública de credenciamento de operadoras $\mathrm{n}^{\circ}$ 058/2000. Disponível em: <dtr2001. saude.gov.br/bvs/publicacoes/profae_ ro.pdf>. Acesso em: 15 out. 2005.

2001d. Edital de convocatória públi-

ca de credenciamento de operadoras $n^{\circ}$ 059/2000. Disponível em: <dtr2001. saude.gov.br/bvs/publicacoes/profae_ se.pdf>. Acesso em: 15 out. 2005.
SEMINÁRIO CERTIFICAÇÃO DE COMPETÊNCIAS PARA A ÁREA DA SAÚDE: os desafios do Profae. 2001, Brasília. Anais. Brasília: Ministério da Saúde, 2001.

SILVA, Pedro L. B.; BIASOTO JR., Geraldo. 2003. Políticas públicas e processos de implementações: o caso do Profae. In: MS (Ministério da Saúde). $1^{\circ}$ Fórum Nacional do Profae: construindo uma política pública de formação profissional em saúde. Brasília: Ministério da Saúde, parte 1, p. 92-112. Relatório final.

UNESCO. 2006. Educação e profissionalização de trabalhadores da área de enfermagem - Profae. Disponível em: $<$ www.unesco.org.br/areas/educacao/ institucional/projetos/edsaude/profae/ mostra_documento $>$. Acesso em: 15 out. 2005.

UNICAMP (Universidade Estadual de Campinas). Núcleo de Estudos de Políticas Públicas. 2004. Avaliação institucional do Profae e definição de parâmetros para o estabelecimento de sistemas de acompanhamento do mercado de trabalho em saúde, especialmente em enfermagem. São Paulo. Relatório final.

VIEIRA, Ana Luiza S. 1990. Formação do atendente de enfermagem no Brasil: um desafio. Cadernos de Saúde Pública, v. 6, n. 1, p. 62-73.

Recebido em 14/10/2005

Aprovado em 19/07/2006 